Plant Tissue Cult. \& Biotech. 28(1): 1-11, 2018 (June)

$\overline{\mathrm{PTC \& B}}$

\title{
In vitro Clonal Multiplication of Two Grape (Vitis spp.) Rootstock Genotypes
}

\author{
M. Alizadeh ${ }^{*}$, S.K. Singh, V.B. Patel and P.S. Deshmukh ${ }^{2}$ \\ Division of Fruits and Horticultural Technology, IARI, New Delhi, India. \\ Key words: Micropropagation, Vitis rootstocks, Nodal segment
}

\begin{abstract}
Single node segments were used to initiate in vitro cultures in two grape rootstocks namely, Dogridge (Vitis champini) and H-144 (Vitis vinifera $\times V$. labrusca). Culture establishment was enhanced using different growth regulators, while BAP was found essential for culture initiation in both genotypes. Less success $(38.31 \%)$ was obtained in culture establishment of $\mathrm{H}-144$ but it exhibited better vegetative growth and rooting and ex vitro performance as compared to Dogridge. Higher shoot multiplication rate (12 micro-cuttings per culture) was recorded in $\mathrm{H}-144$ while only 9 micro-cuttings per subculture were registered in Dogridge. Addition of activated charcoal to the rooting medium was found beneficial with enhancement of rooting and reduction in time to root initiation in both genotypes. The results suggested that multiplication of these two grape rootstock genotypes can be carried out efficiently by means of direct in vitro regeneration using nodal segments. In vitro performance of these two genotypes was also compared during different stages of micropropagation.
\end{abstract}

\section{Introduction}

Modern fruit growing creates an ever-increasing demand for new cultivars and rootstocks. The importance of rootstocks is widely recognized, which in terms of their influence on yield and productivity are not less important than the grafted scions. On the other hand, a large number of commercial micropropagation ventures were reported so far all over the world (Lakshmi et al. 1982, Shekhawat et al. 1998) and several of them have targeted rootstocks owing to robustness of this technique (Webster 1995). Besides mass multiplication and production of highly uniform plantlets, it allows screening genotypes for various in vitro induced stresses which are also vital aspects. The potential for integration of

*Author for correspondence: <mahdializadeh@gau.ac.ir>. ${ }^{1}$ Horticulture Department, Faculty of Plant Production, Gorgan University of Agricultural Sciences \& Natural Resources, Gorgan, Golestan, Iran.

${ }^{2}$ Division of Plant Physiology, IARI, New Delhi, India. 
micropropagation to viticulture is numerous. Several reports have elucidated micropropagation of $V$. vinifera (Chee and Pool 1982, Reisch 1986, Singh et al. 2004) as well as muscadine grapes (Lee and Wetzstein 1990, Gray and Benton 1991, Sudarsono and Goldy 1991, Thies and Graves 1992, Torregrosa and Bouquet 1995, Roubelakis-Angelakis 2001). However, different species may vary in their performance under in vitro conditions (Poudel et al. 2005, Hassan and Zayed 2018). Thus the protocol developed for one cultivar or species may not be equally applicable to another cultivar or species (San Perdro et al. 2017). Hence, present authors studied the in vitro culture ability and micropropagtion of two diverse grape rootstock genotypes.

\section{Materials and Methods}

The field-grown, 5-year-old mother plants of the two grape rootstocks, viz. Dogridge (Vitis champini) and H-144 (Vitis vinifera $\times$ V. labrusca) were selected from the Main Orchard, Division of Fruits and Horticultural Technology, IARI, New Delhi. Besides proper maintenance, the mother plants were sprayed thrice with carbendazim (Bavistin ${ }^{\circledR} @ 2 \mathrm{~g} \Lambda$ ) at three days intervals prior to explant collection.

In vitro culture was initiated using single-node segments $(1.5-2 \mathrm{~cm}$ long) procured from fresh mature canes in the month of March. The explants were thoroughly washed with tap water $(30 \mathrm{~min})$ and agitated in a solution of carbendazim (Bavistin ${ }^{\circledR} @ 2 \mathrm{~g} /$ ) along with 8-HQC (200 mg $\Lambda$ ) for $1 \mathrm{hr}$. These were then transferred to laminar air-flow hood, where surface sterilization was done using $\mathrm{HgCl}_{2}(0.1 \%)$ for $7 \mathrm{~min}$ followed by at least three times rinsing with autoclaved double distilled water. Explants were then inoculated in test tubes (25 $\times 150 \mathrm{~mm}$ ) containing culture initiation medium. MS was used as basal medium for culture initiation as well as shoot proliferation/rooting medium. A combination of BAP $(2.0-4.0 \mathrm{mg} / 1)$, Kin $(2.0-4.0 \mathrm{mg} / \mathrm{A})$ individually or along with $0.2 \mathrm{mg} / 1 \mathrm{NAA}$ was used for culture initiation medium. However, shoot proliferation/rooting medium was supplemented with IBA $(2.0$ or $4.0 \mathrm{mg} / \mathrm{l})$ either singly or in combination with activated charcoal (200 mg/). All media used in the study were supplemented with $30 \mathrm{~g} / 1$ sucrose and solidified with 8.0 $\mathrm{g} / \mathrm{l}$ Agar-Agar. The $\mathrm{pH}$ was adjusted to 5.8 prior to autoclaving $\left(1.05 \mathrm{~kg} / \mathrm{cm}^{2}\right.$ for 15 min.)

Shoots developed on established cultures were excised from original explants as two-node micro-cuttings and inoculated either for rooting or further proliferation.

The in vitro rooted 21-day-old plantlets were transferred to glass jars with polypropylene cap containing coco peat: perlite: vermiculite (2: 1: 1). The potting 
mixture was moistened with half strength of MS macro- and micronutrients devoid of organics and subjected to autoclaving prior to plantlet transfer. The glass jars were then shifted to cool white fluorescent lights $\left(227 \mu \mathrm{mol} / \mathrm{m}^{2} / \mathrm{sec}\right)$ with controlled photoperiod $(16 / 8 \mathrm{hrs})$ and $\left.26 \pm 1^{\circ} \mathrm{C}\right)$ temperature. The polypropylene caps were loosened gradually after three weeks and finally removed completely. The growing plantlets were then misted with sterile distilled water containing $0.1 \%$ carbendazim $(\mathrm{w} / \mathrm{N})$ at regular intervals. One hardened plantlets were transferred to ex vitro glasshouse conditions during 6 to 7th week after transfer. Plantlets cultured in plastic pots were filled with sand: soil: FYM (2: 1: 1) and irrigated with normal tap water. In addition, the experimental plantlets were weekly sprayed with one fourth strength MS salts solution ( $\mathrm{pH}$ 5.8).

\section{Results and Discussion}

The present investigation was carried out in vitro multiplication of two grape rootstock genotypes through nodal segments following direct regeneration pathway. The effect of different plant growth regulators on culture establishment and time taken to bud sprouting is presented in Table 1. Culture initiation was achieved successfully for both genotypes but the results were less satisfactory for H-144 genotype and about $60 \%$ of its explants died during the first two weeks after inoculation. Some explants remained green but without bud sprouting for long period, which coincided with medium dehydration or incidence of microbial contamination. It can be attributed to the morphology of axillary buds in H-144 genotype which is bigger in size compared to Dogridge. This situation may lead to getting higher injury during surface sterilization with $\mathrm{HgCl}_{2}$. However, the genotypic effect also can be considered as one of the reasons in grape micropropagation studies (Chee and Pool 1983, Novak and Juvova 1982/83, Singh et al. 2004, Poudel et al. 2005). Culture establishment was enhanced using different growth regulators and BAP was found essential for culture initiation in both genotypes. Though, BAP at higher concentration (4 $\mathrm{mg} /$ ) enhanced culture establishment and bud sprouting of this genotype but compared to Dogridge the success was still lower. BAP has been reported to be effective in enhancing axillary bud proliferation in several Euvitis species with optimum levels of PGR between 5 and $10 \mu \mathrm{M}$ (Goussard 1981, Gray and Fisher 1985, Harris and Stevenson 1982, Reisch 1986).

Besides good culture establishment, Dogridge showed early bud sprouting (Fig. 1) and more than $70 \%$ explants showed sprouting within the first week following inoculation (data not shown). Data (Table 1) suggest that MS supplemented with BAP $(2.0 \mathrm{mg} / \mathrm{l})$ along with $0.2 \mathrm{mg} / \mathrm{NAA}$ was the best 
combination in order to achieve a higher culture establishment and minimum time to bud sprouting. In this treatment Dogridge sprouted significantly earlier (6.3 days) compared to $\mathrm{H}-144$ in which sprouting took 14.3 days.

Table 1. Effect of different growth regulators on culture initiation in two grape rootstock genotypes.

\begin{tabular}{|c|c|c|c|c|c|c|}
\hline \multirow{2}{*}{$\begin{array}{l}\text { Treatment }(\mathrm{mg} \Lambda) \\
\text { Genotype }\end{array}$} & \multicolumn{3}{|c|}{$\begin{array}{c}\text { Culture establishment } \\
(\%)\end{array}$} & \multicolumn{3}{|c|}{$\begin{array}{l}\text { Time taken to bud sprouting } \\
\text { (days) }\end{array}$} \\
\hline & Dogridge & $\mathrm{H}-144$ & Mean & Dogridge & $\mathrm{H}-144$ & Mean \\
\hline BAP (2.0) & $\begin{array}{c}36.0 \\
(36.87)^{*}\end{array}$ & $\begin{array}{c}31.6 \\
(34.20)^{*}\end{array}$ & $\begin{array}{c}33.8 \\
(35.55)^{*}\end{array}$ & 8.7 & 16.4 & 12.55 \\
\hline BAP (4.0) & $\begin{array}{c}50.1 \\
(45.00)\end{array}$ & $\begin{array}{c}42.6 \\
(40.74)\end{array}$ & $\begin{array}{c}46.35 \\
(42.88)\end{array}$ & 9.4 & 15.1 & 12.25 \\
\hline $\mathrm{BAP}(2.0)+\mathrm{NAA}(0.2)$ & $\begin{array}{c}68.7 \\
(55.98)\end{array}$ & $\begin{array}{c}38.3 \\
(38.23)\end{array}$ & $\begin{array}{c}53.5 \\
(47.01)\end{array}$ & 6.3 & 14.3 & 10.3 \\
\hline $\mathrm{BAP}(4.0)+\mathrm{NAA}(0.2)$ & $\begin{array}{c}53.4 \\
(46.95)\end{array}$ & $\begin{array}{c}41.2 \\
(39.93)\end{array}$ & $\begin{array}{c}47.3 \\
(43.45)\end{array}$ & 6.7 & 16.1 & 11.4 \\
\hline Kin (2.0) & $\begin{array}{c}32.4 \\
(34.70)\end{array}$ & $\begin{array}{c}34.1 \\
(35.73)\end{array}$ & $\begin{array}{c}33.25 \\
(35.18)\end{array}$ & 7.3 & 15.8 & 11.55 \\
\hline Kin (4.0) & $\begin{array}{c}30.8 \\
(33.71)\end{array}$ & $\begin{array}{c}36.7 \\
(37.29)\end{array}$ & $\begin{array}{l}33.75 \\
(35.4)\end{array}$ & 8.6 & 17.2 & 12.9 \\
\hline $\operatorname{Kin}(2.0)+$ NAA $(0.2)$ & $\begin{array}{c}43.5 \\
(41.27)\end{array}$ & $\begin{array}{c}40.8 \\
(39.70)\end{array}$ & $\begin{array}{c}42.15 \\
(40.46)\end{array}$ & 9.6 & 14.8 & 12.2 \\
\hline Kin $(4.0)+$ NAA $(0.2)$ & $\begin{array}{c}45.3 \\
(42.30)\end{array}$ & $\begin{array}{c}41.2 \\
(39.93)\end{array}$ & $\begin{array}{c}43.25 \\
(41.09)\end{array}$ & 10.1 & 16.4 & 13.25 \\
\hline Mean & $\begin{array}{c}45.02 \\
(42.05)\end{array}$ & $\begin{array}{c}38.31 \\
(38.05)\end{array}$ & & 8.46 & 15.76 & \\
\hline Treatment $(\mathrm{T})$ & & $\mathrm{CD}$ at $5 \%$ & 1.10 & & & 0.40 \\
\hline Genotype (G) & & & 1.64 & & & 0.57 \\
\hline $\mathrm{T} \times \mathrm{G}$ & & & 3.29 & & & 1.15 \\
\hline
\end{tabular}

*ArcSin $\sqrt{ } \%$ transformed values.

Application of Kin for culture establishment was also studied (Table 1). Two genotypes exhibited shoddier response to Kin than BAP. Kin ( $2 \mathrm{mg} /)$ gave minimum culture establishment (34.1\%) in H-144 genotype, but interestingly, high culture establishment $(40.8 \%)$ was achieved using the same treatment along with NAA $(0.2 \mathrm{mg} /)$. These results suggest that irrespective of the cytokinin source, addition of low level of auxin is necessary in order to attain a higher culture establishment. This essential role of NAA was evident in all treatment combinations. 


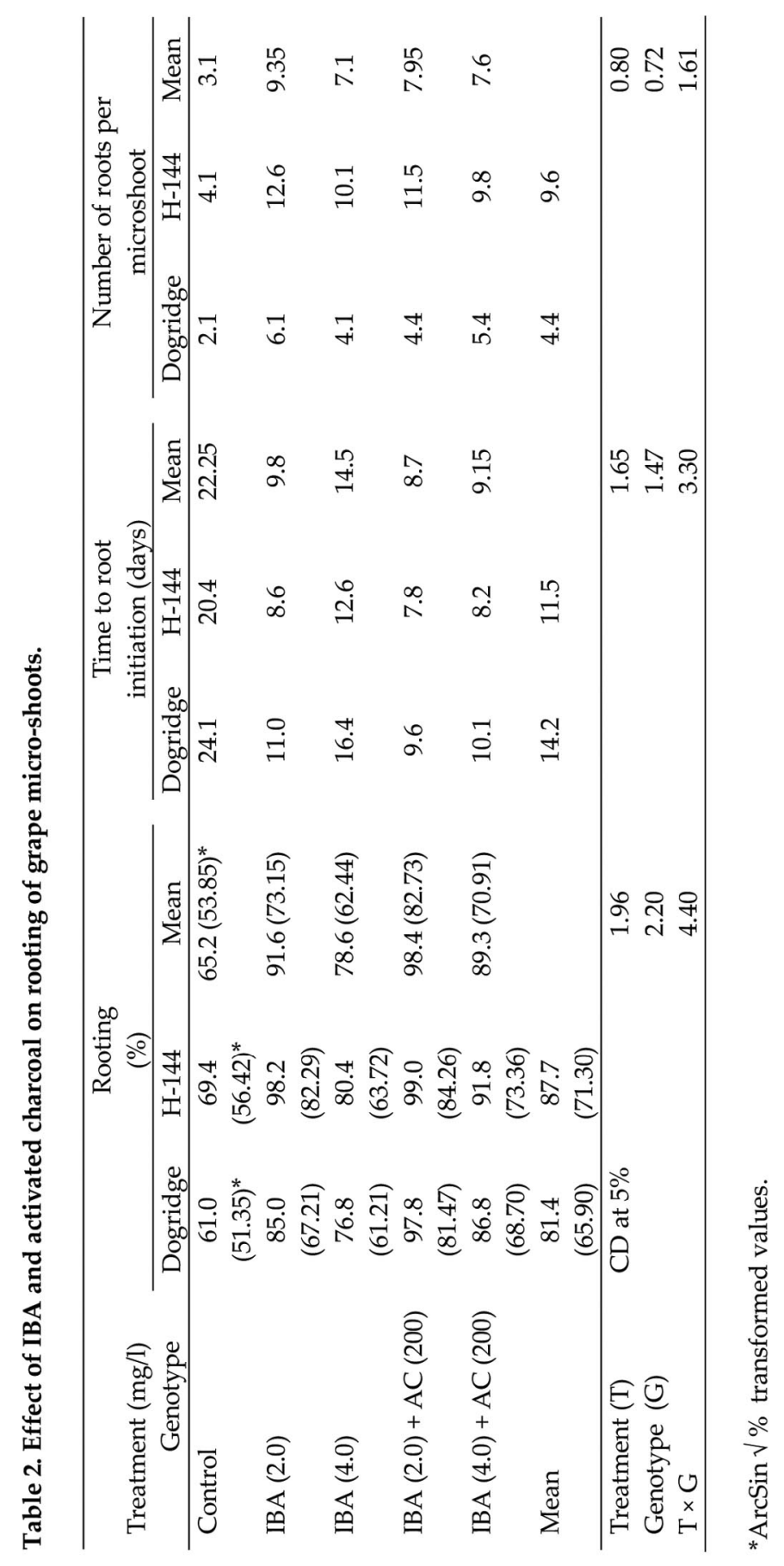



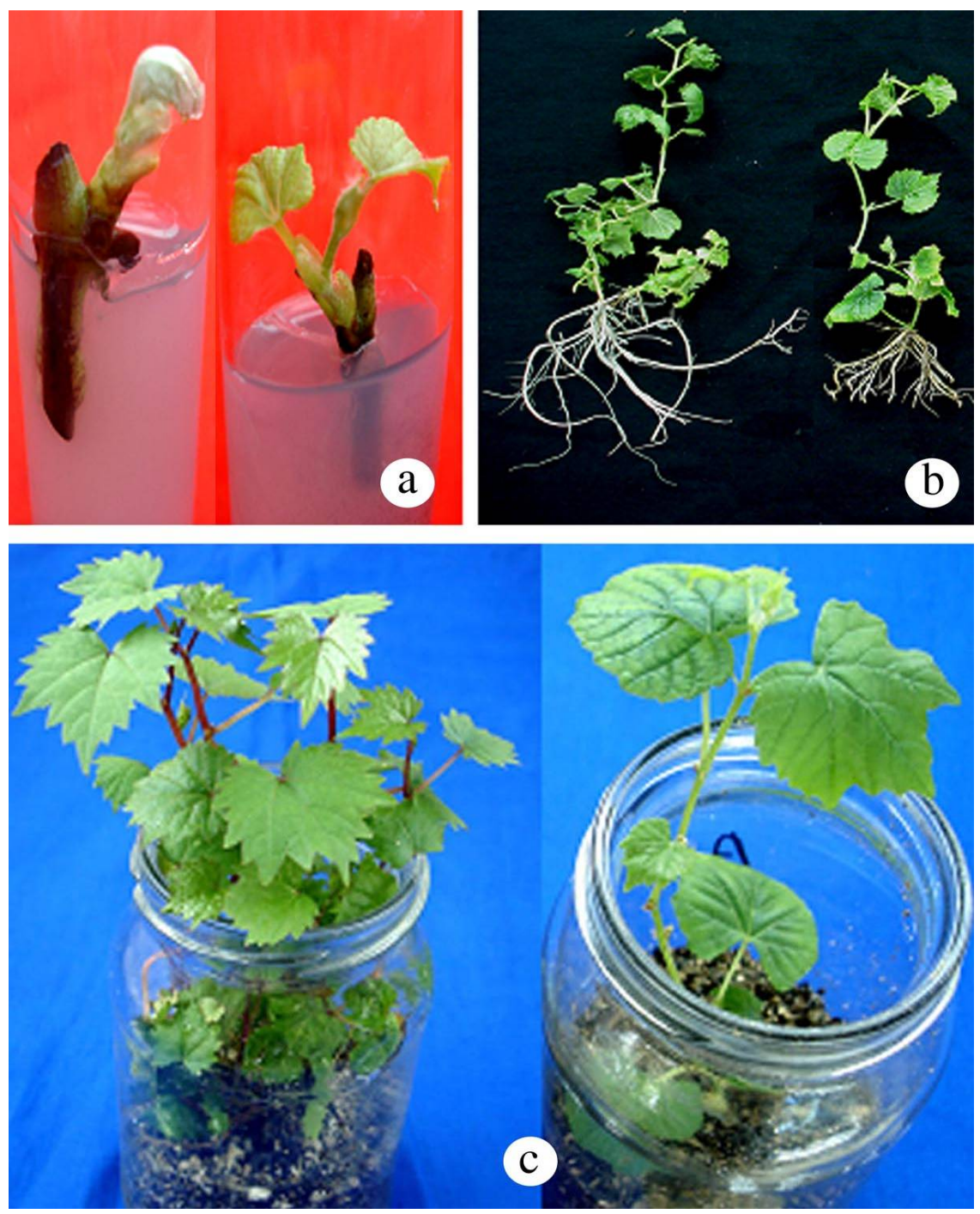

Fig. 1. In vitro performance of $\mathrm{H}-144$ (left) and Dogridge genotypes during different stages of micropropagation. (a) Culture initiation 20 DAI (days after inoculation), (b) Rooting and shoot proliferation 35 DAI and (c) In vitro hardening 45 DAI.

The effectiveness of Kin for culture establishment of grapevine has been previously reported from Japan (Poudel et al. 2005). They demonstrated that Kin was more effective than 2-ip and BAP for culture establishment in a wild grape genotype. However, earlier studies recommended BAP as an effective cytokinin for grapevine culture establishment (Novak and Juvova 1982/83, Singh et al. 2004). Sudarsono and Goldy (1991) on the other hand, reported that thidiazuron (TDZ) alone or in combination with BA or Kin was effective for in vitro culture 
establishment in Vitis rotundifolia. Present experiments suggest that low concentrations $(2 \mathrm{mg} \Lambda)$ of BAP or Kin may be used for culture initiation of these two grape rootstocks. However, an addition of low level of NAA $(0.2 \mathrm{mg} /)$ is indispensable.

When single-node microcuttings were used for subsequent subculturing, the rate of mortality and explant injury during transfer to fresh medium increased. Besides, more time was needed for bud sprouting as well as root initiation (data not shown). Therefore, to avoid these problems, two-node microcuttings were used either for rooting or shoot proliferation throughout the study.

IBA has been reported to have favoured root induction in several species including kiwifruit (Monette 1986), walnut (Tang et al. 2000) and grape (Mhatre et al. 2000, Singh et al. 2004, Barreto and Nookaraju 2007). Two IBA concentrations (2 and $4 \mathrm{mg} /$ ) used in this study, differed in their effects on the rooting parameters. Both concentrations alone or in combination with activated charcoal (200 $\mathrm{mg}$ /) significantly enhanced the rooting percentage of the two grape genotypes as compared to the hormone-free medium.

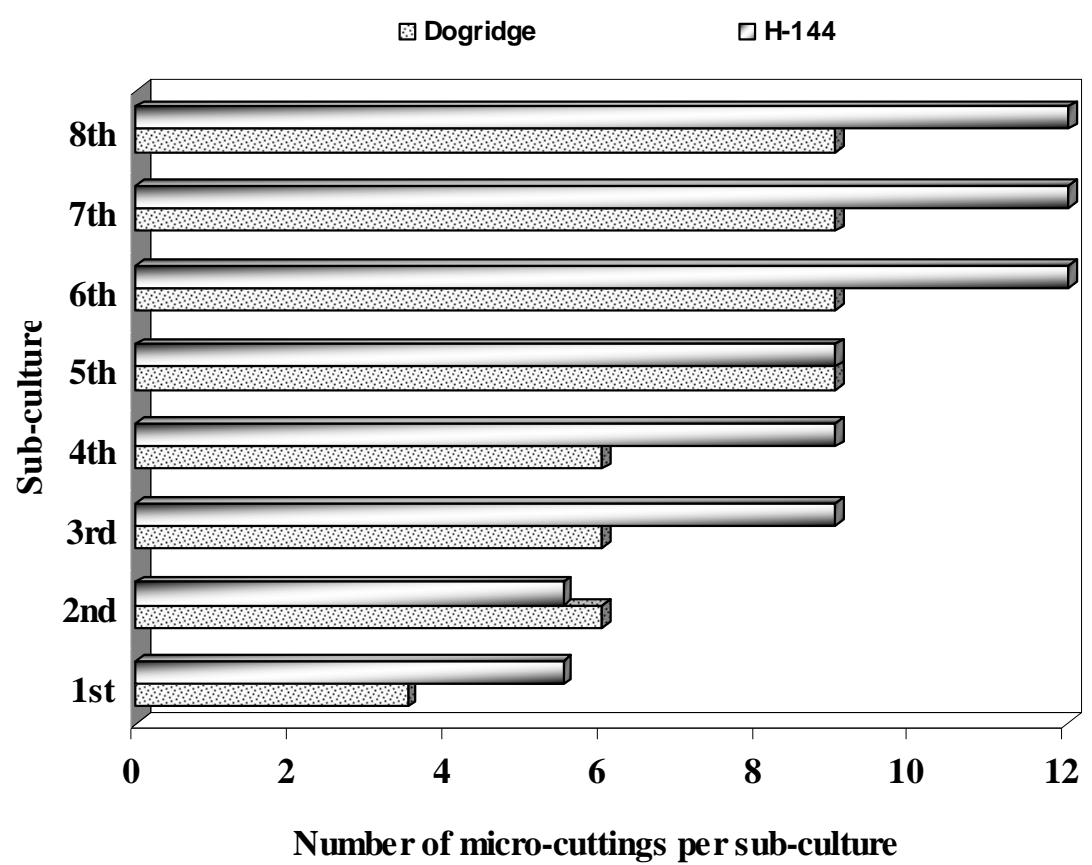

Fig. 2. Average number of microcuttings recovered per subculture (Multiplication rate).

Despite low response in culture establishment of H-144, once the culture is established vegetative growth and rooting were found superior to Dogridge (Fig. 1). The genotype showed early root initiation (11.5 days), also the mean number 
of roots per inoculated micro-shoot was recorded higher (9.6) than Dogridge (4.4) (Table 2). That was considered as a desirable character especially to attain a higher plantlet survival during ex vitro transfer or hardening stage.

Addition of activated charcoal was found beneficial in order to enhance rooting ability. Media supplemented with activated charcoal showed higher rooting for both the genotypes (Table 2). Since activated charcoal leads to darkening of the media (Proskauer and Berman 1970), it provides an environment conducive to the accumulation of photo-sensitive auxin or cofactors (Druart et al. 1982). Some reports have also emphasized that activated charcoal absorbs agar impurities (Kohlenbach and Wernicke 1978) and phenols (Johnsson 1983) and as a result induces root initiation. In the present study, the main objective for integration of activated charcoal to the medium was minimization of phenolics exuded from grapevine tissues to avoid media browning or necrosis of explants. However, stimulative effect of this compound on rooting can be considered as a positive point in micropropagation of woody species including grapevine.

Cobalt chloride, activated charcoal and PG (1, 3, 5-trihydroxy benzene) along with IBA treatment had beneficial effect on rooting of in vitro-derived shoots of Decalepis hamiltonii. These two compounds were found useful for hardening and survival of in vitro-derived plants upon transfer to field (Reddy et al. 2001).

The average number of microcuttings recovered per subculture in the two genotypes increased gradually during eight successive subcultures (Fig. 2). The H-144 plantlets showed a higher vegetative growth and as a result a higher number of microcuttings (11 to 13) were recovered as compared to Dogridge $(8-10)$. The number of microcuttings produced per subculture became stabilized following 3rd subculture and was found to be almost constant after 5th subculture.

Poor acclimation and establishment of plantlets in the greenhouse has been a hindrance noticeable complication toward commercial production of grapevine (Swartz and Lindstrom 1986). In this study, both the genotypes were satisfactorily transferred to the glasshouse using glass jars with polypropylene cap (Fig. 1). However, the level of success was higher in H-144 genotype and $87.75 \%$ of the plantlets survived. The survival rate of Dogridge plantlets was lower $(72.35 \%)$ and more time was also needed for plantlets in ex vitro transfer, i.e. 45.8 days. Recently, similar strategy has been used for acclimation of two $V$. vinifera grape varieties (Singh et al. 2004). They observed that tissue culture raised plantlets grew vigorously compared to plants derived from cuttings. It may be due to the carryover effect of plant growth regulators. 
Monitoring vegetative growth on 60 days after transfer to glasshouse, demonstrated that micropropagated plantlets of H-144 attained significantly longer vine length and a greater number of leaves even under glasshouse conditions (Table 3).

Table 3. Hardening of grape plantlets using glass jars with polypropylene cap.

\begin{tabular}{lcccc}
\hline Genotypes & $\begin{array}{c}\text { Plantlet survival } \\
(\%)\end{array}$ & $\begin{array}{c}\text { Time to ex vitro } \\
\text { transfer } \\
\text { (day) }\end{array}$ & $\begin{array}{c}\text { Mean vine } \\
\text { length } \\
(\mathrm{cm})^{* *}\end{array}$ & $\begin{array}{c}\text { No. of } \\
\text { leaves** }\end{array}$ \\
\hline Dogridge & $72.35(58.24)^{*}$ & 45.8 & 23.3 & 26.8 \\
H-144 & $87.75(69.47)$ & 42.8 & 18.3 & 19.6 \\
Mean & $80.05(63.44)$ & 44.3 & 20.8 & 23.2 \\
CD at $5 \%$ & 5.82 & 2.51 & 1.92 & 2.67 \\
\hline
\end{tabular}

${ }^{*} \operatorname{ArcSin} \sqrt{ } \%$ transformed values. ${ }^{* *}$ sixty days after transfer to glasshouse.

The results suggested that multiplication of these two grape rootstocks can be carried out efficiently by means of direct shoot proliferation using nodal segments from field grown vines. The procedure can be used for other tissue culture based techniques, i.e. micrografting, in vitro screening for different biotic and abiotic stresses, induced in vitro mutation studies, etc. Furthermore, commercial application of this technique would aid in providing a large number of healthy rootstocks for grafting any desired scion variety.

\section{Acknowledgements}

The authors are grateful to Mr. Surendra Pal, Technical officer for helpful assistance during micropropagation and maintenance of in vitro raised plantlets in the glasshouse.

\section{References}

Barreto MS and Nookaraju A (2007) Effect of auxin types on in vitro and ex vitro rooting and acclimation of grapevine as influenced by substrates. Indian J. Hort. 64(1): 5-11.

Chee R and Pool RM (1982) The effects of growth substances and photoperiod on the development of shoot apices of Vitis cultured in vitro. Scientia Hort. 16: 17-27.

Chee R and Pool RM (1983) In vitro vegetative propagation of Vitis: Application of previously defined culture conditions to a selection of genotypes. Vitis 22: 363-374.

Druart P, Kevers C, Boxus P, and Gaspar T (1982) In vitro promotion of root formation by apple shoots through darkness effect on endogenous phenols and proxidases. Z. Pflanzenphysiol 108: 429-436. 
Goussard PG (1981) Effect of cytokinins on elongation, proliferation and total mass of shoots derived from shoot apices of grapevine cultured in vitro. Vitis 20: 228-234.

Gray DG and Benton CM (1991) In vitro micropropagation and plant establishment of muscadine grape cultivars (Vitis rotundifolia). Plant Cell Tiss. Org. Cult. 27: 7-14.

Gray DL and Fisher LC (1985) In vitro shoot propagation of grape species, hybrids and cultivars. Proc. Fla. State Hort. Soc. 98: 172-174.

Harris RE and Stevenson JH (1982) In vitro propagation of Vitis Vitis 21: 22-32.

Hassan SAM and Zayed NS (2018) Factor Controlling micropropagation of fruit trees: A review. Science International 6: 1-10.

Johnsson L (1983) Effects of activated charcoal in anther cultures. Physiol. Plant 59: 397-403.

Kohlenbach HV and Wernicke W (1978) Investigations on the inhibitory effect of agar and the function of active carbon in anther culture. Z. Pflanzenphysiol 86: 463-472.

Lakshmi Sita G, Vaidyanathan CS and Ramakrishnan T (1982) Applied aspects of plant tissue culture with special reference to tree improvement. Curr. Sci. 51: 88-92.

Lee $\mathbf{N}$ and Wetzstein HY (1990) In vitro propagation of muscadine grape by axillary shoot proliferation. J. Amer. Soc. Hort. Sci. 115(2): 324-329.

Mhatre M, Salunkhe CK and Rao PS (2000) Micropropagation of Vitis vinifera L.: Towards an improved protocol. Scientia Hort. 84: 357-363.

Monette PL (1986) Micropropagation of kiwifruit using non-axenic shoot tips. Plant Cell Tiss. Org. Cult. 6(1):73-82.

Novak FJ and Juvova Z (1982) Clonal propagation of grapevine through in vitro axillary bud culture. Scientia Hort. 18: 231-240.

Poudel PR, Kataoka I and Mochioka R (2005) Effect of plant growth regulators on in vitro propagation of Vitis ficifolia var. ganebu and its interspecific hybrid grape. Asian J. Plant Sci. 4(5): 466-471.

Proskauer J and Berman R (1970) Agar culture medium modified to approximate soil conditions. Nature 227: 1161-1163.

Reddy B, Giridhar P and Ravishankar GA (2001) In vitro rooting of Decalepis hamiltonii, an endangered shrub, by auxins and root-promoting agents. Curr. Sci. 81(11-10):14791481.

Reisch BI (1986) Influence of genotype and cytokinins on in vitro shoot proliferation of grapes. J. Amer. Soc. Hort. Sci. 111(1):138-141.

Roubelakis-Angelakis KA (2001) Molecular Biology and Biotechnology of the Grapevine. Kluwer Academic Publishers, London.

SanPedro T, Peiro R, Villanova J, Olmos A and Gisbert C (2017) In vitro propagation of Vitis vinifera L. cv. 'Monastrell'. Electronic Journal of Biotechnology $27: 80-83$.

Shekhawat NS, Mughal MH, Johri BM and Srivastava PS (1998) Indian contribution to plant tissue and organ culture. In: Plant Tissue Culture and Molecular Biology: Applications and Prospects. (Ed. P. S. Srivastava). Narosa Publishing House, New Delhi. pp. 751-811.

Singh SK, Khawale RN and Singh SP (2004) Techniques for rapid in vitro multiplication of Vitis vinifera L. cultivars. J. Hort. Sci. Biotech. 19(2): 267-272. 
Sudarsono A and Goldy RG (1991) Growth regulator and axillary bud position effects on in vitro establishment of Vitis routondifoila. Hort.Sci. 26(3): 304-307.

Tang H, Ren Z, Krczal G (2000) Improvement of English walnut somatic embryo germination and conversion by desiccation treatments and plantlet development by lower medium salts. In Vitro Cellular Dev. Biol. Plant 36(1): 47-50.

Thies KL and Graves CH (1992) Meristem micropropagation protocols for Vitis rotundifolia Michx. Hort. Sci. 27(5): 447- 449.

Torregrosa L and Bouquet A (1995) In vitro propagation of Vitis $\times$ Muscadinia hybrids by microcuttings or axillary budding. Vitis 34(4): 237-238.

Webster AD (1995) Temperate fruit tree rootstock propagation. New Zealand J. Crop Hort. Sci. 23: 355-372. 